\title{
Investigating Effects of Superparamagnetic Iron Oxide Nanoparticles on Candida albicans Biofilm Formation
}

\author{
Fatemeh Golipour (MSc) \\ Department of Microbiology, Faculty \\ of Basic Sciences, Hamedan Branch, \\ Islamic Azad University, Hamedan, \\ Iran \\ Reza Habibipour (PhD) \\ Department of Microbiology, Faculty \\ of Basic Sciences, Hamedan Branch, \\ Islamic Azad University, Hamedan, \\ Iran \\ Leila Moradihaghgou (PhD) \\ Department of Microbiology, Faculty \\ of Basic Sciences, Hamedan Branch, \\ Islamic Azad University, Hamedan, \\ Iran \\ Corresponding author: Reza \\ Habibipour \\ Tel: +989183169760 \\ Email: habiby.reza@gmail.com \\ Address: Department of \\ Microbiology, Islamic Azad \\ University, Hamedan Branch, \\ Hamedan, Iran \\ Received: 27 Dec 2018 \\ Revised: 20 May 2019 \\ Accepted: 22 May 2019 \\ (c) (i) (9) \\ This work is licensed under a Creative \\ Commons Attribution 4.0 License.
}

\section{ABSTRACT}

Background and Objectives: Candida albicans is one of the most common fungal pathogens that can form biofilm, particularly on surface of medical devices. In recent years, C. albicans has shown increased resistance to antifungal agents. In this experimental study, we aimed to study effects of superparamagnetic iron oxide nanoparticles $\left(\mathrm{Fe}_{3} \mathrm{O}_{4}\right.$ nanoparticles or SPION) on biofilm formation by C. albicans.

Methods: First, the SPI0N were synthesized by chemical co-precipitation. The formation of nanoparticles was confirmed by Fourier-transform infrared spectroscopy and $X$ ray diffraction. Minimum inhibitory concentration (MIC) and minimum fungicidal concentration (MFC) of SPI0N were determined. Then, antibiofilm effects of the nanoparticles were investigated by enzyme-linked immunosorbent assay. Finally, data were analyzed using SPSS 22.0 at significance level of 0.05 .

Results: According to the results of $X$-ray diffraction, the SPION had a mean diameter of about $70 \mathrm{~nm}$. MIC and MFC values of SPION against C. albicans were $100 \mathrm{ppm}$ and $200 \mathrm{ppm}$ which reduced biofilm formation by $87.2 \%$ and $100 \%$, respectively. SPION showed significant inhibitory effects on C. albicans growth and biofilm formation.

Conclusion: Based on the findings, SPI0N may be considered as a novel family of fungicidal compounds. However, further studies are necessary to evaluate the safety of these nanoparticles for treatment of fungal infections in humans.

Keywords: Candida albicans; Biofilms; SPI0N; Nanoparticles.

This paper should be cited as: Golipour F, Habibipour R, Moradihaghgou L [Investigating Effects of Superparamagnetic Iron Oxide Nanoparticles on Candida albicans Biofilm Formation]. mljgoums. 2019; 13(6): 44-50 


\section{INTRODUCTION}

Candida albicans is an opportunistic fungus and a part of the normal gut flora $(1,2)$. Although the microorganism is not normally harmful, overgrowth of the fungus can result in candidiasis and candidemia (3). The fungus is characterized by multiple virulence factors such as biofilm formation and protease production (4). The main steps of biofilm formation include attachment of fungi to surface, establishment of cellular interactions and formation of colonies $(5,6)$. In recent decades, biofilms have caused serious challenges in management and treatment of various infectious diseases (7). Compared to non-biofilm forming or planktonic cells, cells within biofilms could survive in an environment containing up to 1,000 fold concentrations of antifungals (8).

The small size (10 to $100 \mathrm{~nm}$ ) of nanoparticles (NPs) makes them suitable candidates for biofilm inhibition and treatment of drugresistant infections (10). Recently, much interest has been given to the use of metal oxide NPs (MNPs) in various industries (11). Particularly, $\mathrm{Fe}_{3} \mathrm{O}_{4}$ NPs have emerged as multi-potential agents with notable properties including simple separation under external magnetic fields, high surface area, large surface-to-volume ratio and low toxicity (12). Furthermore, the use of MNPs as magnetic fluid hyperthermia inductors could limit biofilm formation and may be used for treatment of resistant fungal infections (13). Evidently, electromagnetic attachment between positively charged metal NPs and the negatively charged microorganisms and the subsequent oxidization could lead to immediate elimination of the microorganisms (14). In this study, we aimed to investigate effects of $\mathrm{Fe}_{3} \mathrm{O}_{4}$ NPs (SPION) on biofilm formation by $C$. albicans.

\section{MATERIALS AND METHODS}

$\mathrm{Fe}_{3} \mathrm{O}_{4}$ NPs (SPION) were prepared by chemical co-precipitation of $1.5 \mathrm{mmol}$ $\mathrm{FeCl}_{2} \cdot 4 \mathrm{H}_{2} \mathrm{O}$ (Merck, Germany) and $3.0 \mathrm{mmol}$ $\mathrm{FeCl}_{3} \cdot 6 \mathrm{H}_{2} \mathrm{O}$ (Merck, Germany) in a $0.01 \mathrm{M}$ $\mathrm{HCl}$ solution (Merck, Germany). The solution was rapidly mixed with $80 \mathrm{ml}$ of $2 \mathrm{M}$ ammonia solution (Merck, Germany) and stirred uniformly for one hour at room temperature under nitrogen gas. The precipitate was washed with absolute ethanol (Merck, Germany) and separated using a constant external magnetic field. The procedure continued until the $\mathrm{pH}$ of the output solution matched the $\mathrm{pH}$ of the washing solution. Magnetic nanocrystals were dried at $70{ }^{\circ} \mathrm{C}$ under vacuum conditions (15). Nanoparticles were characterized by Fourier-transform infrared spectroscopy (FTIR, PerkinElmer Frontier) and X-ray diffraction.

C. albicans PTCC 5207 was purchased from the Iranian Research Organization for Science and Technology (IROST), cultured on Potato Dextrose Agar (PDA) (Scharlau, Spain) and Potato Dextrose Broth (PDB) (Scharlau, Spain) media and incubated at $25{ }^{\circ} \mathrm{C}$ for 24 hours.

Inoculum preparation was done in polystyrene, flat bottom 96-well microplates (JET BIOFIL, Canada). Each well was filled with $100 \mu \mathrm{l}$ of different concentrations of NPs $(25,50,100$, $150,200,500,600,1000 \mathrm{ppm}), 180 \mu \mathrm{l}$ of PDB and $20 \mu \mathrm{l}$ of a yeast suspension equivalent to 0.5 MacFarland standard. Each concentration was inoculated in triplicate. The negative control wells contained only PDB and distilled water. The positive control wells contained PDB, distilled water (concentration 0) and yeast. The microplates were incubated at $25^{\circ} \mathrm{C}$ for 24 hours. This inoculum was used for future testing. Minimum inhibitory concentration (MIC) was determined according to the CLSI M27 guidelines with some modification (16). MIC was described as the lowest concentration of SPION that prevented the growth of $C$. albicans (17). Minimum fungicidal concentration (MFC) was described as the lowest concentration of NPs which produced no measurable growth on the plate (18). The MFC was determined by transferring $10 \mu \mathrm{l}$ from wells with MIC values over the threshold value into the PDA plate, followed by 24 hours of incubation at $25^{\circ} \mathrm{C}$.

Crystal violet staining was carried out to evaluate biofilm formation. Briefly, after 24 hours of culture, all wells were washed trice with $300 \mu \mathrm{l}$ of ringer (Merck, Germany) to remove loosely attached cells. Then, $300 \mu 1$ of methanol (Merck, Germany) were used to stabilize Candida biofilms. After $30 \mathrm{~min}$, methanol was aspirated at room temperature, $150 \mu \mathrm{l}$ of $0.1 \%$ crystal violet (Merck, Germany) were added to the wells, and the microplate was incubated at room temperature for $5 \mathrm{~min}$. Next, the wells were softly rinsed under running tap water and dried at room 
temperature. Next, $150 \mu l$ of acetic acid (33\% v/v; Sigma-Aldrich, USA) were added to wash out the stain from the wells. Finally, absorbance of each well was read at $630 \mathrm{~nm}$ in an ELISA Reader (BioTek, Elx 800, USA) (19). The optical density cut off (ODC) for the microtiter-plate test was defined as three standard deviations above the mean OD of negative controls (20). Accordingly, the isolates were categorized as non- (OD $\leq$ ODC), weak- [ODC < OD $\leq(2 \times$ ODC $)$, moderate- $[(2 \times$ ODC $)<$ OD $\leq(4 \times$ ODC $)]$ and strong- $[(4 \times \mathrm{ODC})<\mathrm{OD}]$ biofilm forming.

The percentage of biofilm inhibition was calculated based on the following formula (21): Percent biofilm inhibition $=\left[\left(\mathrm{OD}_{\mathrm{C}}-\right.\right.$ $\left.\left.\mathrm{OD}_{\mathrm{B}}\right)-\left(\mathrm{OD}_{\mathrm{T}}-\mathrm{OD}_{\mathrm{B}}\right) /\left(\mathrm{OD}_{\mathrm{C}}-\mathrm{OD}_{\mathrm{B}}\right)\right] \times 100 . \mathrm{In}$ the formula, $\mathrm{OD}_{\mathrm{C}}, \mathrm{OD}_{\mathrm{B}}$, and $\mathrm{OD}_{\mathrm{T}}$ represent OD of negative control, positive control (blank) and treatments, respectively. Statistical analysis of data was carried out using SPSS 22.0 and Microsoft Excel 2010 at significance level of 0.05 .

\section{RESULTS}

SPION FTIR absorption spectrum showed a band at $581 \mathrm{~cm}^{-1}$, which corresponded to the $\mathrm{Fe}-\mathrm{O}$ vibration (Figure 1). This absorption peak verifies the synthesis of iron nanocrystals in the magnetite phase (15). The X-ray diffraction demonstrated that the SPION have an approximately similar size and mean diameter of about $70 \mathrm{~nm}$.

Concentrations of $100 \mathrm{ppm}$ and $200 \mathrm{ppm}$ were determined as the MIC and MFC, respectively. The highest level of biofilm formation was observed at $25 \mathrm{ppm}$. As expected, increasing the concentration of SPION to $200 \mathrm{ppm}$ significantly increased the biofilm inhibition activity against $C$. albicans. Furthermore, the most effective concentration for inhibition of biofilm formation was $200 \mathrm{ppm}$ (Figure 2 and Table 1).

We recorded a $48.8 \%$ reduction of biofilm formation by C. albicans at $25 \mathrm{ppm}$ of SPION, while no biofilm (100\% inhibition) was formed at $200 \mathrm{ppm}$ of SPION.

Figure 1- (A) FTIR analysis of SPION. (B) X-ray diffraction patterns of magnetic nanocrystals.

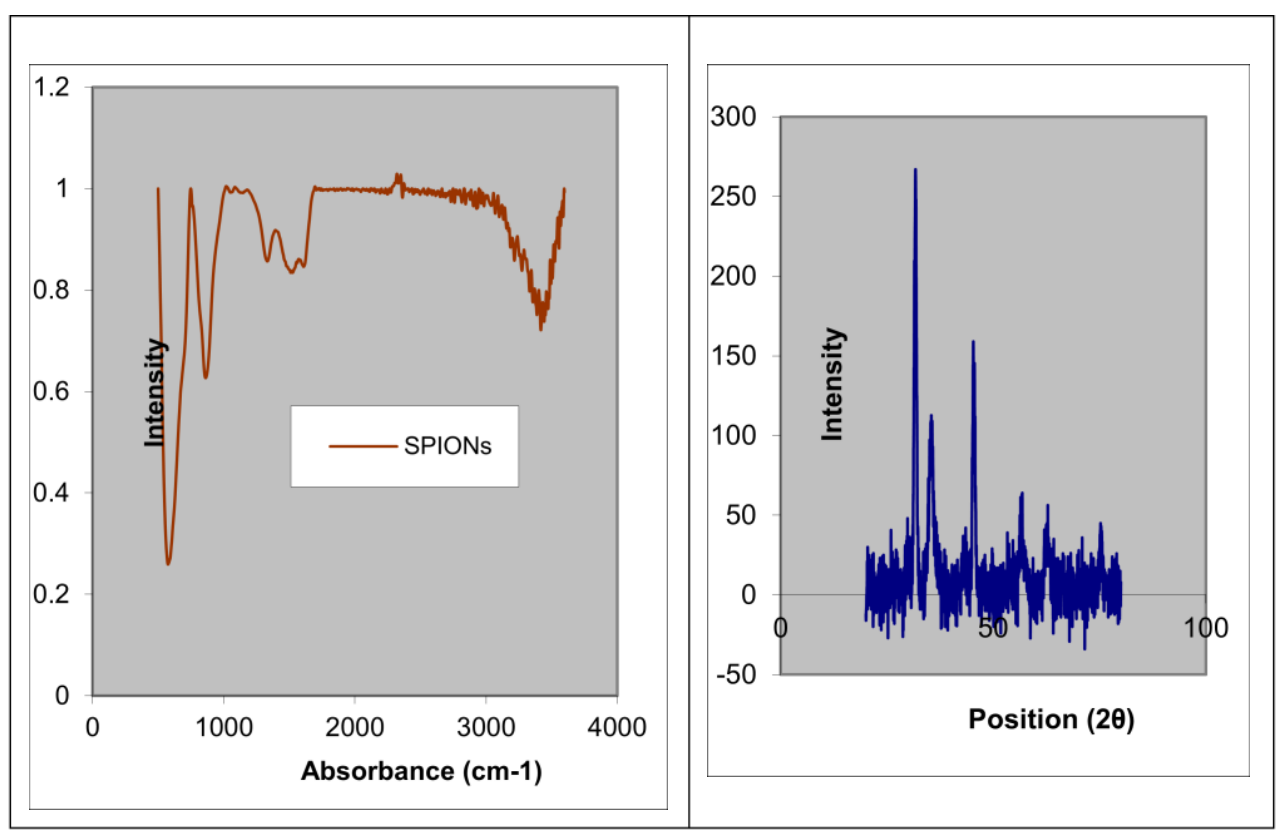




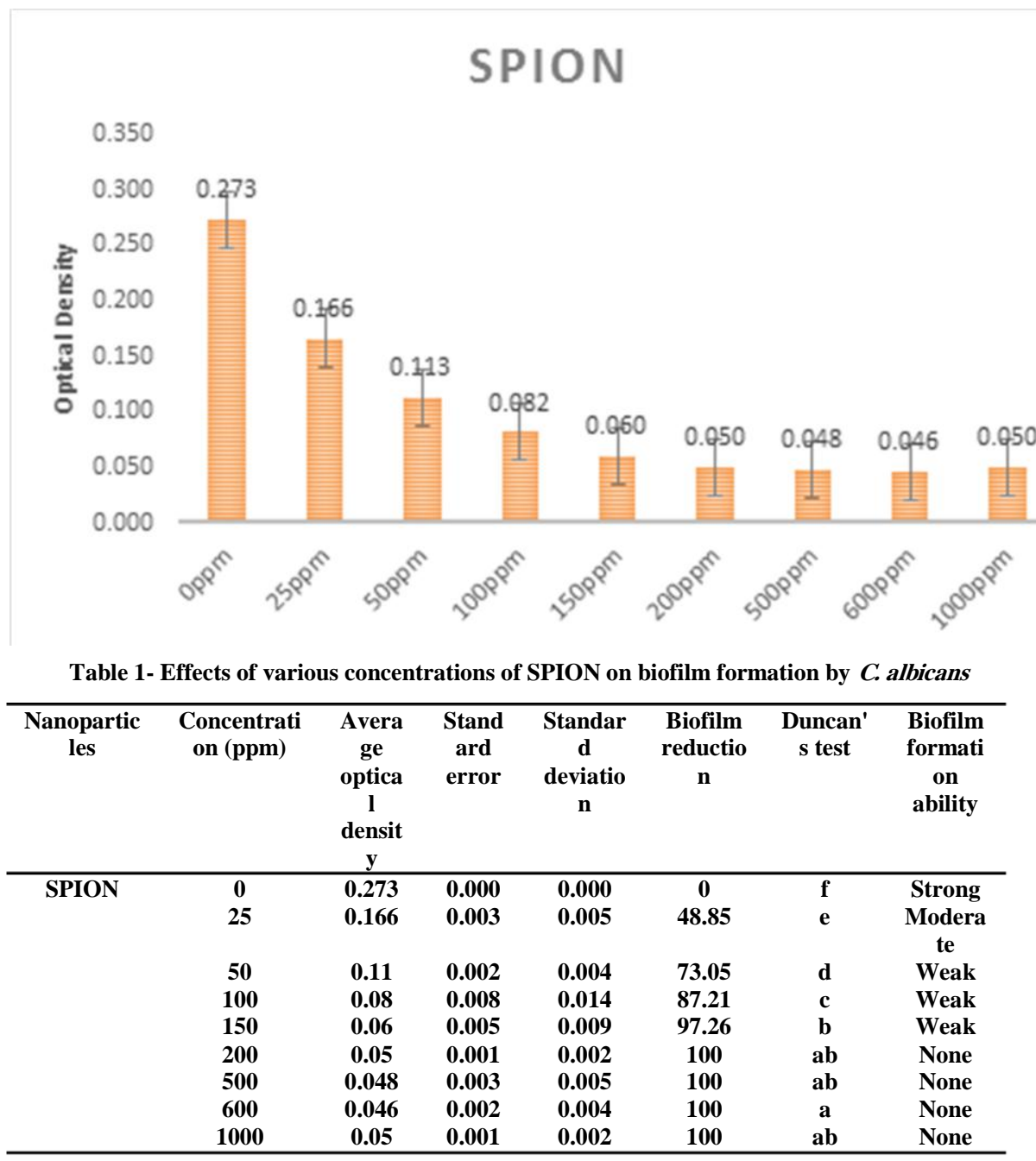

\section{DISCUSSION}

The antimicrobial effect of metal NPs is related to their high surface area to volume ratio (22). Interestingly, during the synthesis of FeNPs, produced colloidal magnetite can be easily oxidized in acidic suspensions in two steps: cationic defects are created on the surface by reduction of $\mathrm{Fe}^{2+}$ ions and then diffusion of $\mathrm{Fe}^{3+}$ ions takes place in the crystal lattice (23). Since a magnetic field can increase the absorption of NPs into bacterial biofilms, it can be used to eliminate biofilms as well as to treat infectious diseases $(24,25)$. The shape and size of NPs can influence their antimicrobial activity (26). It is reported that penetration of zerovalent iron NPs $\left(\mathrm{Fe}^{0}\right)$ sized 10-80 nm into Escherichia coli membrane could lead to bacterial growth inhibition by interacting with intracellular oxygen, thereby causing oxidative stress and disruption of the cell membrane (27).
The antibiofilm effects of metal NPs have been demonstrated in numerous studies. Silver NPs can interact with the membrane surface of C. albicans and Saccharomyces cerevisiae and form "pits" that eventually result in cell death (28). These NPs can also cause apoptotic cell death in $C$. albicans by enhancing hydroxide ions (29). It has been reported that reactive oxygen species (ROS)-dependent anticandidal property of $\mathrm{ZnO}$ NPs is due to the production of ROS in a concentration-dependent manner (30). Regarding the antifungal effect of cerium oxide NPs (CeNP), it is believed that the interaction between cerium and components of the fungal cell wall can cause irreversible changes, such as blocking fungal enzymatic activity (31). It has also been reported that the antibiofilm activity of mesoporous $\mathrm{TiO}_{2} \mathrm{NPs}$ could be due to release of attached bioactive elements (32). It is also thought that the 
presence of $\mathrm{Fe}_{3} \mathrm{O}_{4}$ NPs result in ROS production, which consequently prevents Staphylococcus aureus growth (27). A study on effects of CeNPs on $C$. albicans reported that $17 \mathrm{ppm}$ (lowest) CeNP could reduce the viability of the fungus, while concentration of 170 ppm completely inhibited the growth of $C$. albicans (32). Given the obtained MIC and MFC values for SPION in our study, we can conclude that the antifungal effect of CeNPs against $C$. albicans is far more than that of SPION. In another study, the $\mathrm{MIC}_{50}$ value of $\mathrm{CuO}$ NPs was 1000 ppm against three Candida species (26), which indicates that these NPs have weaker antifungal activity compared to SPION. The MIC of AgNPs for preventing growth of sessile $C$. albicans ATCC 90028 was $1.5 \mathrm{ppm}$ (33), which is significantly less than the MIC value obtained from SPION. In our study, increasing the concentration of SPION increased the antifungal and antibiofilm activity of the NPs, which has been also observed in other studies $(34,35)$. In a study, antifungal effects of four MNPs including magnesium oxide $(\mathrm{MgO})$, zinc oxide $(\mathrm{ZnO})$, silicon oxide $\left(\mathrm{SiO}_{2}\right)$ and copper oxide $(\mathrm{CuO})$ were investigated against C. albicans. Interestingly, MIC of nano- $\mathrm{SiO}_{2}$ and nano-MgO was higher than $3200 \mathrm{ppm}$, while MIC and MFC of nano-ZnO were 200 ppm and $400 \mathrm{ppm}$, respectively (29).

\section{REFERENCES}

1. Deorukhkar SC, Saini S. Why Candida species have emerged as important nosocomial pathogens. Int J Curr Microbiol App Sci. 2016; 5(1): 533-545. http://dx.doi.org/10.20546/ijcmas.2016.501.054.

2. Shao LC, Sheng CQ, Zhang WN. Recent advances in the study of antifungal lead compounds with new chemical scaffolds. Yao xue xue bao $=$ Acta pharmaceutica Sinica. 2007; 42(11): 1129-36. PMID: 18300466.

3. Rajeevan S, Thomas M, Appalaraju B. Characterisation and antifungal susceptibility pattern of Candida species isolated from various clinical samples at a tertiary care Centre in South India. Indian Journal of Microbiology Research. 2016; 3(1): 53-7. DOI: 10.5958/2394-5478.2016.00014.5.

4. Jalal M, Ansari MA, Ali SG, Khan HM, Rehman S. Anticandidal activity of bioinspired ZnO NPs: effect on growth, cell morphology and key virulence attributes of Candida species. Artificial Cells, Nanomedicine, and Biotechnology. 2018; 46: 912-25. DOI: 10.1080/21691401.2018.1439837.
In our study, $200 \mathrm{ppm}$ of SPION completely inhibited biofilm formation and growth of $C$. albicans. In a previous study, $50 \mathrm{ppm}$ of SeNP prevented biofilm formation by 60 to $70 \%$ (36), which is similar to the antibiofilm effects produced by the same concentration of SPION. In another study, AuNPs at concentrations $\geq 20 \mathrm{ppm}$ could inhibit metabolic activity of biofilms more than $80 \%$ (37).

A concentration range of $10-2000 \mathrm{ppm}$ SPION was capable of eliminating up to $25 \%$ of Staphylococcus epidermidis present in a 48 hour old biofilm (38). At concentrations of 125 and $250 \mathrm{ppm}, \mathrm{ZnONPs}$ could decrease biofilm formation by $C$. albicans by $62 \%$ and $85 \%$, respectively (4).

\section{CONCLUSION}

Based on the findings, SPION could be considered as a novel family of fungicidal compounds.

\section{ACKNOWLEDGEMENTS}

The authors wish to thank the Islamic Azad University of Hamedan for their kind support in completing this project.

\section{CONFLICT OF INTREST}

All authors certify that there is no conflict of interest.

5. Nabavizadeh M, Abbaszadegan A, Gholami A, Kadkhoda Z, Mirhadi H, Ghasemi Y, et al. Antibiofilm efficacy of positively charged imidazolium-based silver nanoparticles in Enterococcus faecalis using quantitative real-time PCR. Jundishapur Journal of Microbiology. 2017; 10(10): 1-7. DOI: 10.5812/jjm.55616.

6. Frederick MR, Kuttler C, Hense BA, Eberl HJ. A mathematical model of quorum sensing regulated EPS production in biofilm communities. Theoretical Biology and Medical Modelling. 2011; 8(1): 8. DOI: 10.1186/1742-4682-8-8.

7. Song T, Duperthuy M, Wai S. Sub-optimal treatment of bacterial biofilms. Antibiotics. 2016; 5(2): 23. DOI: 10.3390/antibiotics5020023.

8. Nett JE, Cain MT, Crawford K, Andes DR. Optimizing a Candida biofilm microtiter plate model for measurement of antifungal susceptibility by tetrazolium salt assay. Journal of clinical microbiology. 2011; 49(4): 1426-33. DOI: 10.1128/JCM.02273-10. 
9. Pelgrift RY, Friedman AJ. Nanotechnology as a therapeutic tool to combat microbial resistance. Advanced drug delivery reviews. 2013; 65(13-14): 180315. https://doi.org/10.1016/j.addr.2013.07.011.

10 . Singh M, Manikandan S, Kumaraguru AK. Nanoparticles: a new technology with wide applications. Research Journal of Nanoscience and Nanotechnology. 2011; 1(1): 1-11. DOI: 10.3923/rjnn.2011.1.11.

11. Grigore ME, Biscu ER, Holban AM, Gestal MC, Grumezescu AM. Methods of synthesis, properties and biomedical applications of $\mathrm{CuO}$ nanoparticles. Pharmaceuticals. 2016; 9(4): 75. DOI: 10.3390/ph9040075.

12. Xu J-K, Zhang F-F, Sun J-J, Sheng J, Wang F, Sun M. Bio and nanomaterials based on $\mathrm{Fe}_{3} \mathrm{O}_{4}$. Molecules. 2014; 19(12): 21506-28. DOI: 10.3390/molecules191221506.

13. Niemirowicz K, Bucki R. Enhancing the fungicidal activity of antibiotics: are magnetic nanoparticles the key? Future Medicine. 2017; 12(15): 1747-49. DOI: 10.2217/nnm-2017-0051.

14. Prabhu YT, Rao KV, Kumari BS, Kumar VS, Pavani T. Synthesis of $\mathrm{Fe}_{3} \mathrm{O}_{4}$ nanoparticles and its antibacterial application. International Nano Letters. 2015; 5(2): 85-92. DOI: 10.1007/s40089-015-0141-Z.

15. Yang T, Shen C, Li Z, Zhang H, Xiao C, Chen S, et al. Highly ordered self-assembly with large area of $\mathrm{Fe}_{3} \mathrm{O}_{4}$ nanoparticles and the magnetic properties. The Journal of Physical Chemistry B. 2005; 109(49): 232336. DOI: 10.1021/jp054291f.

16. Wayne PA. CLSI. References Method for Broth Dilution Antifungal SusceptibulityTesting of Yeasts. 4th ed. CLSI Standard M27.: Clinical and Laboratory Standards Institute. 2017.

17. Liao RS, Rennie RP, Talbot JA. Novel fluorescent broth microdilution method for fluconazole susceptibility testing of Candida albicans. Journal of Clinical Microbiology. 2001; 39(7): 2708-12. DOI: 10.1128/JCM.39.7.2708-2712.2001.

18. Zhang Y, Chen Y-y, Huang L, Chai Z-g, Shen L-J, $\mathrm{Xiao} \mathrm{Y}-\mathrm{h}$. The antifungal effects and mechanical properties of silver bromide/cationic polymer nanocomposite- modified Poly-methyl methacrylate-based dental resin. Scientific reports. 2017; 7(1): 1547. DOI: 10.1038/s41598-017-01686-4.

19. Agarwal R, Singh S, Bhilegaonkar K, Singh V. Optimization of microtitre plate assay for the testing of biofilm formation ability in different Salmonella serotypes. International Food Research Journal. 2011; 18(4): 1493-98.

20. Nyenje ME, Green E, Ndip RN. Biofilm formation and adherence characteristics of Listeria ivanovii strains isolated from ready-to-eat foods in Alice, South Africa. ScientificWorldJournal. 2012;2012:873909. doi: 10.1100/2012/873909.

21. Namasivayam SKR, Preethi M, Bharani A, Robin G, Latha B. Biofilm inhibitory effect of silver nanoparticles coated catheter against Staphylococcus aureus and evaluation of its synergistic effects with antibiotics. International Journal of Biological \& Pharmaceutical Research. 2012; 3(2): 259-65.
22. Thukkaram M, Sitaram S, Subbiahdoss G. Antibacterial efficacy of iron-oxide nanoparticles against biofilms on different biomaterial surfaces. International Journal of biomaterials. 2014; 201: 1-6. http://dx.doi.org/10.1155/2014/716080.

23. Petri-Fink A, Hofmann H. Superparamagnetic Iron Oxide Nanoparticles (SPIONs): From Synthesis to in vivo studies-A Summary of Synthesis, Characterization, In Vito, and In Vivo Investigations of SPIONs With Particular Focus on Surface and Colloidal Properties. IEEE transactions on nanobioscience. 2007; 6(4): 28997. DOI: 10.1109/TNB.2007.908987.

24. Seabra AB, Haddad P, Duran N. Biogenic synthesis of nanostructured iron compounds: applications and perspectives. IET nanobiotechnology. 2013; 7(3): 90-9. DOI: 10.1049/iet-nbt.2012.0047.

25. Shi S-f, Jia J-f, Guo X-k, Zhao Y-p, Chen D-s, Guo $\mathrm{Y}-\mathrm{y}$, et al. Reduced Staphylococcus aureus biofilm formation in the presence of chitosan-coated iron oxide nanoparticles. International Journal of Nanomedicine. 2016; 11: 6499-6506. DOI: 10.2147/IJN.S41371.

26. Amiri M, Etemadifar Z, Daneshkazemi A, Nateghi M. Antimicrobial effect of copper oxide nanoparticles on some oral bacteria and Candida species. Journal of Dental Biomaterials. 2017; 4(1): 347-52. PMID: 28959764.

27. Tran N, Mir A, Mallik D, Sinha A, Nayar S, Webster TJ. Bactericidal effect of iron oxide nanoparticles on Staphylococcus aureus. International Journal of Nanomedicine. 2010; $277-83$. https://doi.org/10.2147/IJN.S9220.

28. Nasrollahi A, Pourshamsian K, Mansourkiaee P. Antifungal activity of silver nanoparticles on some of fungi. International Journal of Nano Dimension. 2011; 1(3): 233-39. DOI: 10.7508/ijnd.2010.03.007.

29. Karimiyan A, Najafzadeh $H$, Ghorbanpour M, Hekmati-Moghaddam SH. Antifungal effect of magnesium oxide, zinc oxide, silicon oxide and copper oxide nanoparticles against Candida albicans. Zahedan Journal of Research in Medical Science. 2015; 17(10): 13. DOI: 10.17795/zjrms-2179.

30. Shoeb M, Singh BR, Khan JA, Khan W, Singh BN, Singh HB, et al. ROS-dependent anticandidal activity of zinc oxide nanoparticles synthesized by using egg albumen as a biotemplate. Advances in Natural Sciences: Nanoscience and Nanotechnology. 2013; 4(3): 035015. DOI: 10.1088/2043-6262/4/3/035015.

31. Farias IAP, Santos CCLD, Sampaio FC. Antimicrobial activity of cerium oxide nanoparticles on opportunistic microorganisms: a systematic review. Biomed Research International. 2018; 3: 1-14. https://doi.org/10.1155/2018/1923606.

32. Ramasamy M, Lee J. Recent nanotechnology approaches for prevention and treatment of biofilmassociated infections on medical devices. BioMed Research International. 2016: 1-17. http://dx.doi.org/10.1155/2016/1851242 .

33. Halbandge SD, Mortale SP, Karuppayil SM. Biofabricated silver nanoparticles synergistically activate amphotericin B against mature biofilm forms of Candida albicans. The Open Nanomedicine Journal. 2017; 4(1): 1-16. DOI: 10.2174/1875933501704010001. 
34. Abd ST, Ali AF. Effect of zinc oxide nanoparticles on Candida albicans of human saliva (in vitro study). European Journal of Medicine. 2015; 4(6): 1892-1900. DOI: 10.13187/ejm.2015.10.235.

35. Ardestani ZS, Falahati M, Alborzi SS, Khozani MA, Khani FR, Bahador A. The effect of nanochitosans particles on Candida biofilm formation. Current Medical

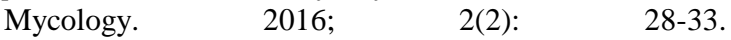
doi: 10.18869/acadpub.cmm.2.2.1.

36. Cremonini E, Zonaro E, Donini M, Lampis S, Boaretti M, Dusi S, et al. Biogenic selenium nanoparticles: characterization, antimicrobial activity and effects on human dendritic cells and fibroblasts. Microbial biotechnology. 2016; 9(6): 758-71. DOI: 10.1111/1751-7915.12374.
37. Yu Q, Li J, Zhang Y, Wang Y, Liu L, Li M. Inhibition of gold nanoparticles (AuNPs) on pathogenic biofilm formation and invation to host cells. Scientific Reports. 2016; 6: 26667. DOI: 10.1038/srep26667.

38. Taylor EN, Webster TJ. The use of superparamagnetic nanoparticles for prosthetic biofilm prevention. International Journal of Nanomedicine. 2009; 4: 145-52. DOI: 10.2147/IJN.S5976. 